\title{
Tranexamic acid in total shoulder arthroplasty and reverse shoulder arthroplasty: a systematic review and meta-analysis
}

Liang-Tseng Kuo ${ }^{1,2,3}$, Wei-Hsiu Hsu ${ }^{1,4}$, Ching-Chi Chi ${ }^{2,4,5^{*}}$ (1) and Jae Chul Yoo ${ }^{6 *+}$

\begin{abstract}
Background: The effects of tranexamic acid (TXA) in the setting of shoulder arthroplasty are unclear. The objective of this study was to examine the effects of TXA in reducing the need for blood transfusions and blood loss in patients undergoing primary total shoulder arthroplasty (TSA) and reverse total shoulder arthroplasty (RTSA).
\end{abstract}

Methods: We conducted a systematic review and meta-analysis of randomized controlled trials (RCTs) and retrospective cohort studies (RCS) that compared outcomes of patients who did and did not receive TXA during TSA or RTSA. We searched Cochrane Central Register of Controlled Trials, EMBASE, and MEDLINE for relevant studies. We assessed the risk of bias of the included studies and calculated pooled risk estimates. The primary outcome was transfusion rate, and secondary outcomes were changes in hemoglobin, estimated total blood loss (ETBL), blood loss via drainage, operative time, hospital stay, overall complications, and thromboembolic events.

Results: We identified 3 RCTs and 3 RCS including 677 patients with 680 shoulders (343 TXA and 337 nonTXA). The random-effects model meta-analysis showed that TXA group had a lower transfusion rate (risk ratio (RR) $0.34,95 \% \mathrm{Cl} 0.14$ to 0.79 ), less change in hemoglobin (mean difference (MD) $-0.64 \mathrm{~g} / \mathrm{dl}, 95 \% \mathrm{Cl}-0$. 81 to -0.46$)$, and reduced ETBL (MD - $249.24 \mathrm{ml}, 95 \% \mathrm{Cl}-338.74$ to -159.74$)$. In patients with RTSA, the TXA group had a lower transfusion rate (RR $0.28,95 \% \mathrm{Cl} 0.14$ to 0.79), less ETBL (MD $-249.15 \mathrm{ml}, 95 \% \mathrm{Cl}-426.60$ to -71.70 ), less change in hemoglobin ( $\mathrm{MD}-0.64 \mathrm{~g} / \mathrm{dl}, 95 \% \mathrm{Cl}-0.86$ to -0.42$)$, and less blood loss via drainage (MD $-84.56 \mathrm{ml}, 95 \% \mathrm{Cl}-145.72 .14$ to -23.39 ) than non-TXA group.

Conclusions: The use of TXA in primary shoulder arthroplasty appears safe, and can reduce transfusion rate, changes in hemoglobin, and perioperative total blood loss, especially in patients with RTSA. Level of Evidence: Systematic Review and meta-analysis, III.

Keywords: Total shoulder arthroplasty, Reverse total shoulder arthroplasty, Tranexamic acid, Blood loss, Transfusion

\footnotetext{
* Correspondence: chingchi@cgmh.org.tw; chingchichi@gmail.com; shoulderyoo@gmail.com

${ }^{\dagger}$ Equal contributors

${ }^{2}$ Centre for Evidence-Based Medicine, Chang Gung Memorial Hospital, Chiayi,

Taiwan

${ }^{6}$ Department of Orthopedic Surgery, College of Medicine, Samsung Medical

Center, Sungkyunkwan University School of Medicine, 81 Irwon-ro,

Gangnam-gu, Seoul 135-710, Republic of Korea

Full list of author information is available at the end of the article
} 


\section{Background}

With improvements in implant design and surgical techniques, total shoulder arthroplasty (TSA) and reverse total shoulder arthroplasty (RTSA) are gaining popularity and are widely indicated for various shoulder conditions including end-stage shoulder arthropathy, cuff tear arthropathy, traumatic shoulder injuries, tumors, and failure of prior arthroplasty. However, shoulder arthroplasty, including both TSA and RTSA, is associated with a considerable risk of perioperative blood loss, and a reported allogeneic blood transfusion rate ranging from $4.3 \%$ to $43 \%$ [1-7]. The risk factors for requiring a transfusion after shoulder arthroplasty include old age, female sex, preoperative anemia, ischemic heart disease, and reverse shoulder replacement [2-4, 6-8].

The complications of blood transfusions include allergic reactions, immunosuppression, infection, and transfusion-related cardiopulmonary injury [9, 10]. A previous study of a healthcare database reported that patients who received a perioperative blood transfusion had a higher risk of medical complications including myocardial infarction, pneumonia, sepsis, and cerebrovascular accidents, as well as venous thromboembolic events and surgical complications including periprosthetic infections, periprosthetic fractures, and mechanical complications [11]. Though sicker patients that are more likely to require transfusions are also more likely to have complications mentioned above such as MI, pneumonia, stroke, etc. It is not likely the transfusion itself that causes these complications.

Many methods are available to reduce perioperative blood loss, including hypotensive anesthesia, hemodilution, autologous blood transfusion, reinfusion drainage, and the use of intravenous or topical tranexamic acid (TXA) [12, 13]. TXA interferes with the process of fibrinolysis and thereby reduces perioperative blood loss and the need for a transfusion [14]. Previous systematic reviews and meta-analyses have shown that the use of TXA in total knee arthroplasty and total hip arthroplasty can reduce blood loss and blood transfusion rates without increasing venous thromboembolism or other complications [15-18]. However, even though a few studies have investigated the use of TXA in shoulder arthroplasty, its effectiveness remains unclear $[19,20]$. To date, few meta-analysis of randomized controlled trials (RCTs) and retrospective cohort studies (RCS) has investigated the effects of TXA in TSA [21, 22]. Even though more current studies on this issue have been published recently $[23,24]$, systematic evaluations of the latest evidence on the use of TXA in shoulder arthroplasty, and especially in RTSA, are lacking. Therefore, to comprehensively examine the effects of TXA in shoulder arthroplasty, we conducted this systematic review and metaanalysis to evaluate outcomes including transfusion rate, total blood loss, changes in postoperative hemoglobin $(\mathrm{Hb})$, operative time, hospital stay and thromboembolic events. Our hypothesis is that TXA can reduce allogenic blood transfusion rate and blood loss effectively in patients with shoulder arthroplasty.

\section{Methods}

Data source and search strategy

We searched the Cochrane Central Register of Controlled Trials (CENTRAL), EMBASE, and MEDLINE from inception to August 15th, 2017 for RCTs and RCS that compared surgical outcomes in patients who did and did not receive TXA during TSA or RTSA. We also checked the references of the included studies for potentially relevant studies. There were no language restrictions.

The key words used in the search included "tranexamic acid", "total shoulder arthroplasty", and "reverse total shoulder arthroplasty". Search details are shown in the supplementary document (see Additional file 1: Appendix 1). We also searched the U.S. National Institutes of Health trials registry (http://clinicaltrials.gov). In addition, we contacted experts in this field for relevant ongoing trials or unpublished studies.

\section{Selection criteria}

Studies were included if they met the following criteria: (1) they were designed as a RCT or RCS; and (2) they compared the outcomes in patients who did and did not receive TXA during TSA or RTSA. There were no restrictions on the route of TXA administration. Two authors (LTK and CCC) independently checked the citations identified from the searches against the inclusion criteria.

\section{Data extraction and risk of bias assessment}

Two authors (LTK and WHH) independently extracted the data from the included trials using a formal data extraction sheet. The items were as follows: first author, year of publication, diagnosis, study design, sample size, participant characteristics (e.g., age and sex), the regimen of TXA (dose and route), and the operative details such as the prosthesis type and surgical approach. Outcome data including operative time (minutes), hospital stay (days), blood loss through an intra-articular drain $(\mathrm{ml})$, estimated blood loss $(\mathrm{ml})$, changes in postoperative $\mathrm{Hb}(\mathrm{g} / \mathrm{dl})$, transfusion rate and complications including overall and thromboembolic events were also extracted. The third author (CCC) arbitrated in cases where LTK and WHH could not agree.

LTK and WHH independently assessed the risk of bias of the included studies, and CCC resolved differences in opinions. The Cochrane Collaboration's tool was used to evaluate the risk of bias of the included 
RCTs. The Cochrane risk of bias tool included the following domains on biased estimates of intervention effects: randomization sequence, allocation concealment, performance bias (blinding of patients and personnel), detection bias (blinding of outcome assessors), attrition bias (incomplete outcome data), selective reporting, and other biases $[25,26]$. For each domain, a high, low, or unclear risk of bias was judged per the quality of the RCT [25]. The Newcastle-Ottawa Scale was applied to assess the bias of the included RCS [27].

The primary outcome was blood transfusion rate. The secondary outcomes included estimated total blood loss, changes in postoperative $\mathrm{Hb}(\mathrm{g} / \mathrm{dl})$, blood loss via the drain (ml), operative time (minutes), hospital stay (days), and thromboembolic and overall complications.

\section{Statistical analysis}

Quantitative analysis was performed for blood loss via drainage, estimated total blood loss, changes in postoperative $\mathrm{Hb}$, operative time, and hospital stay, for which continuous data were presented as mean difference (MD) with a 95\% confidence interval (CI). Dichotomous data including transfusion rate, overall complications, and thrombotic complications were reported as risk ratio (RR) with a 95\% CI. We examined between-study variance using the tau-square ( $(2)$ statistic [26]. $x^{2}$ and $I^{2}$ statistics were used for statistical heterogeneity, and significance was set at $P<0.10 . I^{2}$ values of $0-24.9 \%$, $25-49.9 \%, 50-74.9 \%$, and $75-100 \%$ were assigned as none, low, moderate, and high heterogeneity, respectively [28, 29]. We performed a random-effects model meta-analysis for all outcomes, because we expected clinical heterogeneity across the included RCTs and RCS [30]. For continuous data, if the standard deviation (SD) was not reported, we estimated the mean and variance from the reported median, range, and sample size as previously reported [31]. When the SD and range were not available, variance was estimated from the $P$ value in the $t$ test [26]. A forest plot was used to summarize the results. Review Manager 5.3 (The Nordic Cochrane Centre, The Cochrane Collaboration, 2014) was used for meta-analysis.

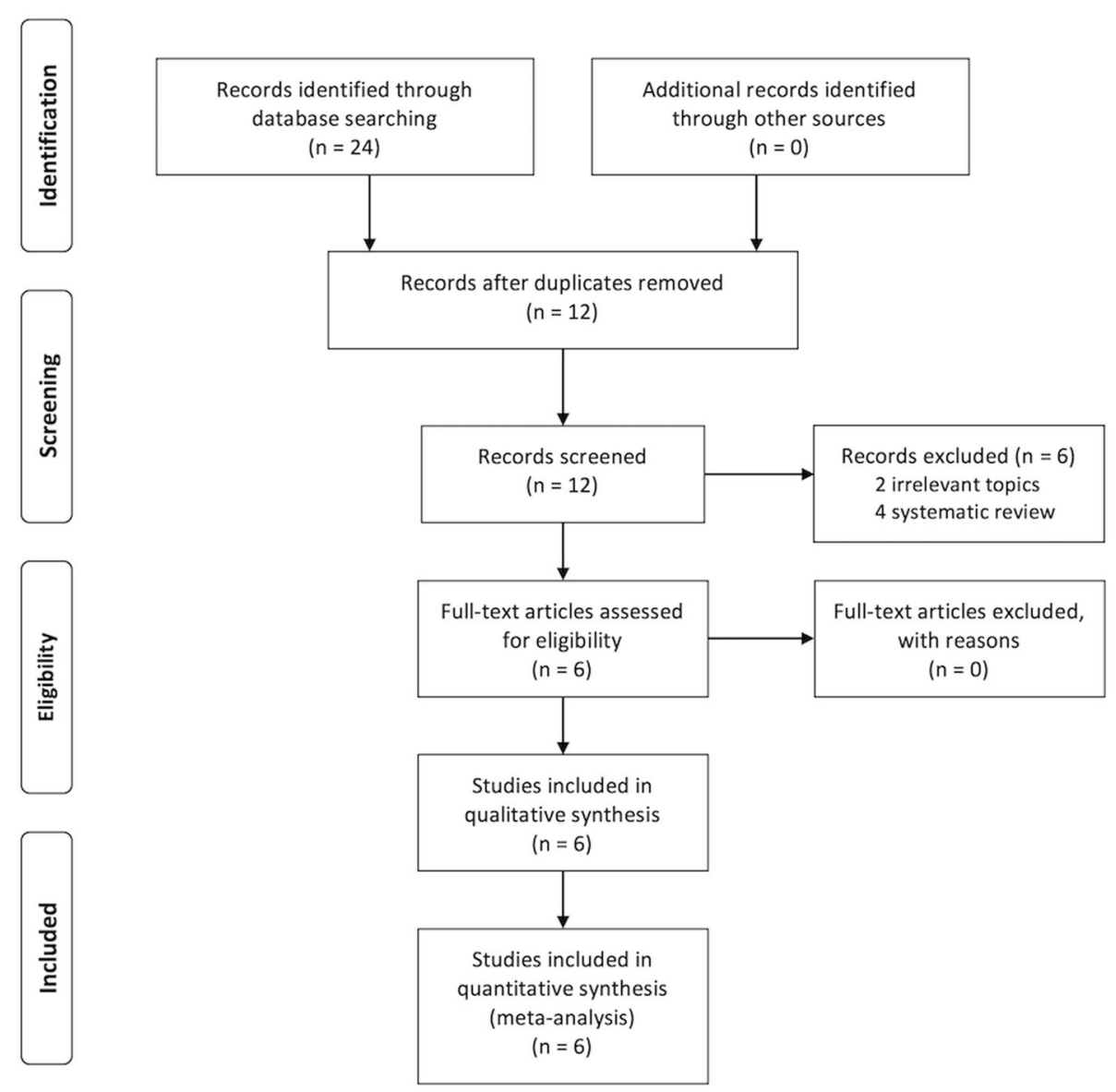

Fig. 1 PRISMA 2009 (Preferred Reporting Items for Systematic Reviews and Meta-Analyses) flow diagram of the study 


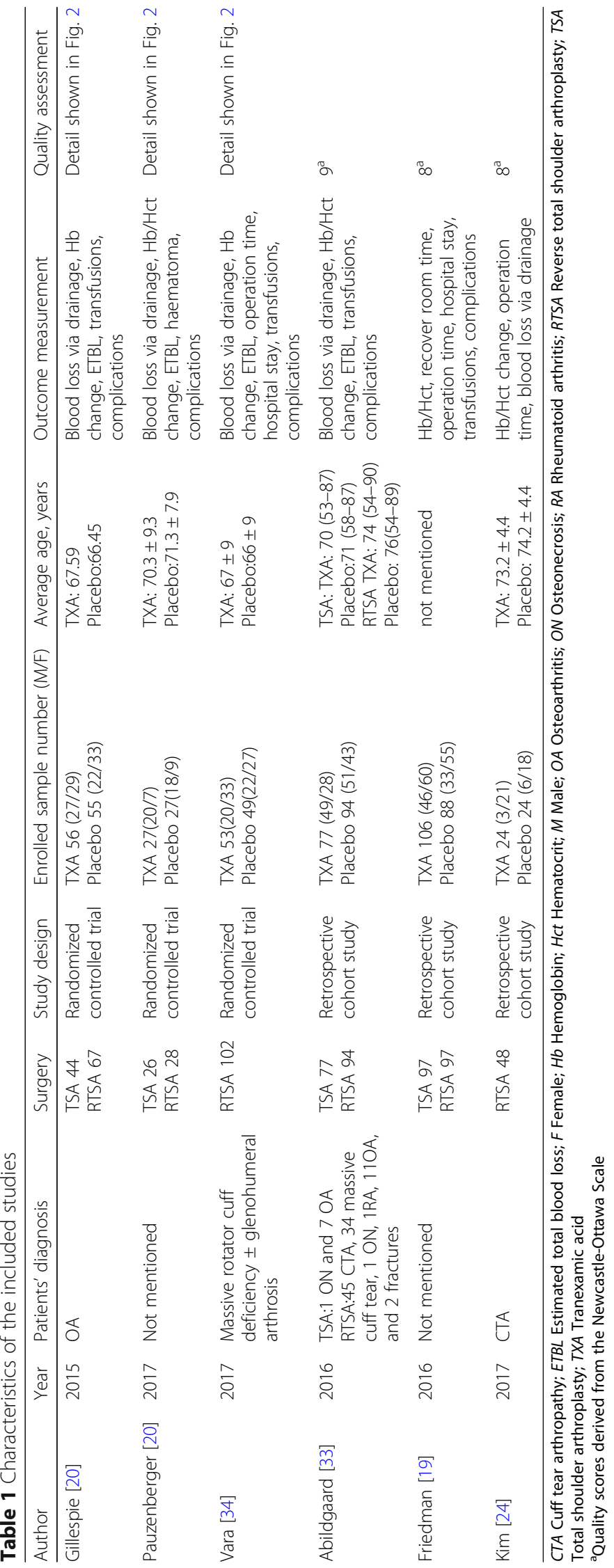




\section{Subgroup analysis}

If data were available, we planned to perform subgroups analysis including:

(1) RCTs alone;

(2)Different routes of TXA administration: intravenous (IV) versus topical;

(3) RTSA or TSA only.

\section{Results}

The details of the study selection process are presented in Fig. 1 [32]. Our search of the MEDLINE, EMBASE, and CENTRAL databases returned 24 published studies. No additional studies were identified from the references of the included studies. After excluding 12 duplicates and 6 studies (two irrelevant topics and four systematic reviews), we finally included the following six studies in this meta-analysis: Abildgaard et al. [33], Friedman et al. [19], Gillespie et al. [20], Kim et al. [24], Pauzenberger et al. [23], and Vara et al. [34].

\section{Study characteristics and patient populations}

The included trials were published between 2015 and 2017 (Table 1). The sample sizes ranged from 48 to 194, with a total 677 patients (680 shoulders, 343 in the TXA group and 337 in the non-TXA group). Three included studies [20, 23, 34] were RCTs that prospectively compared outcomes, and the other three RCS [19, 24, 33] compared results using retrospective analysis (Table 1). Further perioperative characteristics of the included studies are described in Table 2.

\section{Risk of bias of the included studies}

Data on the risk of bias of the six studies included in the meta-analysis are summarized in Table 1 and Fig. 2. The three RCS $[19,24,33]$ were of high quality (NewcastleOttawa Scale score > 7). For the risk of bias of the RCTs, random sequence generation and allocation concealment were not described in two trials [20,34], and therefore the risk of bias was rated as being unclear. Blinding of the surgeon was not explicitly mentioned in one trial [23], which was therefore also rated as having an unclear risk of bias. Other items with regards to the risk of bias were rated as low risk when appraised using the Cochrane Collaboration's tool.

\section{Outcomes}

Summaries of the findings and subgroup analysis are shown in Table 3.

Table 2 Perioperative details of the included studies

\begin{tabular}{|c|c|c|c|c|c|c|}
\hline Author & Year & Intervention & Prosthesis properties & Approach & Transfusion protocol & Thromboprophylaxis \\
\hline Gillespie [20] & 2015 & $\begin{array}{l}\text { TXA: } 2 \mathrm{~g} \text { in } 100 \mathrm{ml} \mathrm{NS} \\
\text { for } 5 \text { min } \\
\text { Placebo: } 100 \mathrm{ml} \mathrm{NS} \\
\text { for } 5 \mathrm{~min}\end{array}$ & $\mathrm{~N} / \mathrm{S}$ & DP & $\begin{array}{l}\text { 1) } \mathrm{Hb}<7.0 \mathrm{~g} / \mathrm{dl} \\
\text { 2) } 7.1 \mathrm{~g} / \mathrm{dl}<\mathrm{Hb} \\
<9.0 \mathrm{~g} / \mathrm{dl}+\text { symptoms }\end{array}$ & $\mathrm{N} / \mathrm{S}$ \\
\hline Pauzenberger [23] & 2017 & $\begin{array}{l}\text { TXA: } 1 \mathrm{~g} \text { TXA intravenously } \\
\text { in } 100 \mathrm{ml} \text { NS, } 2 \text { doses } \\
\text { Placebo: } 100 \mathrm{ml} \text { NS, } 2 \text { doses }\end{array}$ & $\begin{array}{l}\text { TSA (Eclipse; Arthrex Inc., } \\
\text { Naples, Florida) } \\
\text { RTSA (Delta Xtend; DePuy } \\
\text { Synthes, Warsaw, Indiana) }\end{array}$ & DP & $\begin{array}{l}\text { 1) } \mathrm{Hb}<8 \mathrm{~g} / \mathrm{dl} \\
\text { 2) } 8 \mathrm{~g} / \mathrm{dl}<\mathrm{Hb} \\
<10 \mathrm{~g} / \mathrm{dl}+\text { symptoms }\end{array}$ & $\begin{array}{l}\text { Chemical prophylaxis } \\
\text { (subcutaneous } 40 \mathrm{mg} \\
\text { of enoxaparin sodium } \\
\text { + aspirin) }\end{array}$ \\
\hline Vara [34] & 2017 & $\begin{array}{l}\text { TXA: } 10 \mathrm{mg} / \mathrm{kg} \text { IV, } 1 \mathrm{st} \\
\text { dose within } 60 \text { mins before } \\
\text { surgery, } 2 \text { nd dose at wound } \\
\text { closure } \\
\text { Placebo: NS }\end{array}$ & $\begin{array}{l}102 \text { Non-cemented RTSA } \\
\text { (79 Zimmer; } 11 \text { DePuy; } 4 \\
\text { Biomet; } 2 \text { Encore,) }\end{array}$ & DP & $\begin{array}{l}\text { 1) } \mathrm{Hb}<7 \mathrm{~g} / \mathrm{dl} \\
\text { 2) } 7 \mathrm{~g} / \mathrm{dl}<\mathrm{Hb} \\
<9 \mathrm{~g} / \mathrm{dl}+\text { symptoms }\end{array}$ & $\begin{array}{l}\text { Chemical prophylaxis } \\
\text { (subcutaneous heparin } \\
+ \text { oral aspirin) } \\
\text { Mechanical prophylaxis } \\
\text { (compression stockings) }\end{array}$ \\
\hline Abildgaard [33] & 2016 & $\begin{array}{l}\text { TXA: } 1 \mathrm{~g} \text { IV at skin } \\
\text { preparation } \\
\text { Placebo: no TXA }\end{array}$ & $\begin{array}{l}\text { TSA (Bigliani/ Flatow } \\
\text { Anatomical Total Shoulder; } \\
\text { Zimmer, Warsaw, IN, USA) } \\
\text { RTSA (Trabecular Metal } \\
\text { Inverse/Reverse Total } \\
\text { Shoulder, Zimmer) }\end{array}$ & DP & $\begin{array}{l}\text { 1) } \mathrm{Hb}<7 \mathrm{~g} / \mathrm{dl} \\
\text { 2) } 7 \mathrm{~g} / \mathrm{dl}<\mathrm{Hb} \\
<9 \mathrm{~g} / \mathrm{dl}+\text { symptoms }\end{array}$ & $\begin{array}{l}\text { Chemical prophylaxis } \\
\text { was not routinely used } \\
\text { postoperatively }\end{array}$ \\
\hline Friedman [19] & 2016 & $\begin{array}{l}\text { TXA: } 20 \mathrm{mg} / \mathrm{kg} \text { IV } \\
\text { at skin preparation } \\
\text { Placebo: no TXA }\end{array}$ & $\begin{array}{l}\text { RTSA: cemented; brand N/S } \\
\text { TSA: } 90 \% \text { non-cemented; }\end{array}$ & $\mathrm{N} / \mathrm{S}$ & $\mathrm{N} / \mathrm{S}$ & $\mathrm{N} / \mathrm{S}$ \\
\hline Kim [24] & 2017 & TXA: 500 mg IV & $\begin{array}{l}25 \text { DJO Reverse Shoulder } \\
\text { Prosthesis; } 16 \text { Tornier reverse } \\
\text { shoulder prosthesis; } 7 \text { Biomet } \\
\text { Comprehensive Reverse Total } \\
\text { Shoulder Replacement }\end{array}$ & DP & No absolute guideline & $\mathrm{N} / \mathrm{S}$ \\
\hline
\end{tabular}




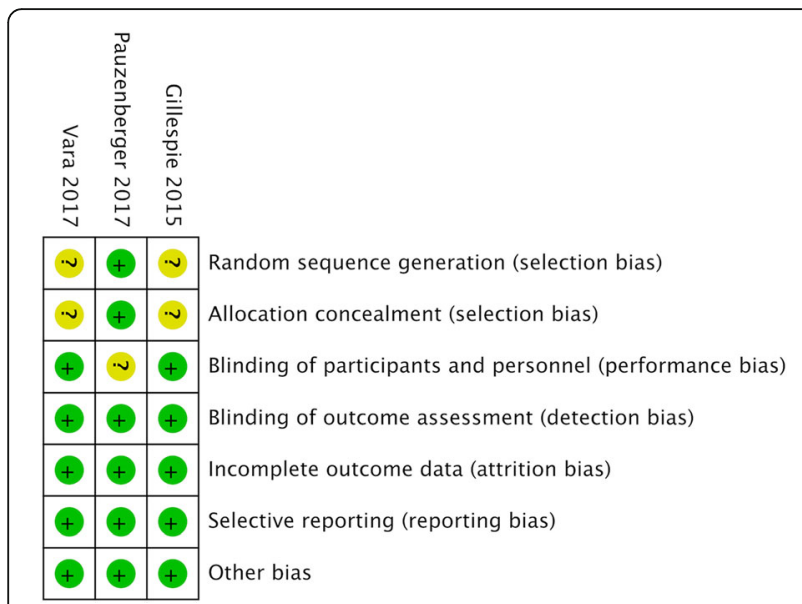

Fig. 2 Risk of bias summary. Authors' judgments about the risk of each bias item for each included study. " +" represents low risk of bias; "?" represents unclear risk of bias; "-" represents high risk of bias

\section{Allogenic blood transfusion rate}

Five included studies $[19,20,23,33,34]$ reported the blood transfusion rate in the TXA and non-TXA groups. The risk of the need for a blood transfusion was lower in the TXA group compared to the nonTXA group (7/319 vs. 20/313, RR 0.34, 95\% CI 0.14 $0.79 ; P=0.01 ; I^{2}=0 \%$; Fig. 3a).

\section{Estimated total blood loss}

Of the included studies, three compared estimated blood loss in the two groups (157 patients in the TXA group vs. 170 patients in the non-TXA group) $[23,33,34]$. The pooled MD for estimated blood loss was $-249.24 \mathrm{ml}(95 \% \mathrm{CI}-338.74$ to $-159.74 \mathrm{ml} ; P$ $<0.00001 ; I^{2}=20 \%$; Fig. 4a), indicating that the postoperative estimated blood loss was $249.24 \mathrm{ml}$ lower in the TXA group compared to the non-TXA group.

Table 3 Summary of findings of shoulder arthroplasty

\begin{tabular}{|c|c|c|c|c|c|c|}
\hline \multirow[t]{2}{*}{ Outcomes } & \multirow[t]{2}{*}{ N } & \multirow{2}{*}{$\begin{array}{l}\text { Patients } \\
\text { (TXA/non-TXA) }\end{array}$} & \multicolumn{2}{|l|}{ Overall effect } & \multicolumn{2}{|c|}{ Heterogeneity } \\
\hline & & & RR or $\mathrm{MD}(95 \% \mathrm{Cl})$ & $P$ & $1^{2}$ & $P$ \\
\hline \multicolumn{7}{|l|}{ Rate of blood transfusion } \\
\hline All included studies & 5 & $319 / 313$ & $0.34[0.14,0.79]$ & 0.02 & $0 \%$ & 0.42 \\
\hline Randomized controlled trials & 3 & $136 / 131$ & $0.23[0.07,0.77]$ & 0.01 & NA & NA \\
\hline RTSA & 4 & $141 / 150$ & $0.28[0.10,0.83]$ & 0.02 & $0 \%$ & 0.47 \\
\hline \multicolumn{7}{|l|}{ Estimated total blood loss (ml) } \\
\hline All included studies & 3 & $157 / 170$ & $-249.24[-338.74,-159.74]$ & $<0.00001$ & $20 \%$ & 0.29 \\
\hline Randomized controlled trials & 2 & $80 / 76$ & $-357.92[-504.25,-211.59]$ & $<0.00001$ & $0 \%$ & 0.87 \\
\hline RTSA & 2 & $95 / 101$ & $-249.15[-426.60,-71.70]$ & 0.006 & $64 \%$ & 0.10 \\
\hline \multicolumn{7}{|c|}{$\mathrm{Hb}$ change within $48 \mathrm{~h}$ after surgery $(\mathrm{g} / \mathrm{dll})^{\mathrm{a}}$} \\
\hline All included studies & 5 & $316 / 310$ & $-0.64[-0.81,-0.46]$ & 0.009 & $0 \%$ & 0.72 \\
\hline Randomized controlled trials & 2 & 109/104 & $-0.65[-1.14,-0.16]$ & $<0.00001$ & $42 \%$ & 0.19 \\
\hline RTSA & 4 & $153 / 158$ & $-0.64[-0.86,-0.42]$ & $<0.0001$ & $0 \%$ & 0.66 \\
\hline IV TXA & 5 & $260 / 255$ & $-0.60[-0.79,-0.41]$ & $<0.0001$ & $0 \%$ & 0.79 \\
\hline Topical TXA & 1 & $56 / 55$ & $-0.90[-1.42,-0.38]$ & 0.0007 & NA & NA \\
\hline \multicolumn{7}{|c|}{ Blood loss via drainage within $48 \mathrm{~h}$ after surgery $(\mathrm{ml})^{\mathrm{a}}$} \\
\hline All included studies & 4 & $160 / 155$ & $-95.41[-139.86,-50.96]$ & $<0.001$ & $65 \%$ & 0.04 \\
\hline Randomized controlled trials & 3 & $136 / 131$ & $-105.78[-159.88,-51.68]$ & 0.001 & $71 \%$ & 0.03 \\
\hline RTSA & 3 & $111 / 106$ & $-84.56[-145.72,-23.39]$ & 0.007 & $80 \%$ & 0.007 \\
\hline IV TXA & 3 & $104 / 100$ & $-110.04[-159.03,-61.06]$ & $<0.0001$ & $65 \%$ & 0.04 \\
\hline Topical TXA & 1 & $56 / 55$ & $-60.00[-103.29,-16.71]$ & 0.007 & NA & NA \\
\hline Operation time (min) & 3 & $183 / 161$ & $-1.08[-4.91,2.74]$ & 0.58 & $0 \%$ & 0.42 \\
\hline Hospital stay (day) & 2 & $159 / 137$ & $-0.04[-0.45,0.37]$ & 0.84 & $75 \%$ & 0.05 \\
\hline Overall complications & 6 & $343 / 337$ & $0.44[0.07,2.96]$ & 0.40 & $0 \%$ & 0.95 \\
\hline Thromboembolic events & 6 & $343 / 337$ & $0.31[0.01,7.40]$ & 0.47 & NA & NA \\
\hline
\end{tabular}

Cl Confidence interval; $\mathrm{Hb}$ Hemoglobin; MD Mean difference; $N$ Number of studies; NA Not applicable; RTSA Reverse total shoulder arthroplasty; TXA Tranexamic acid

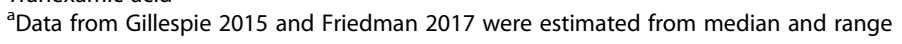



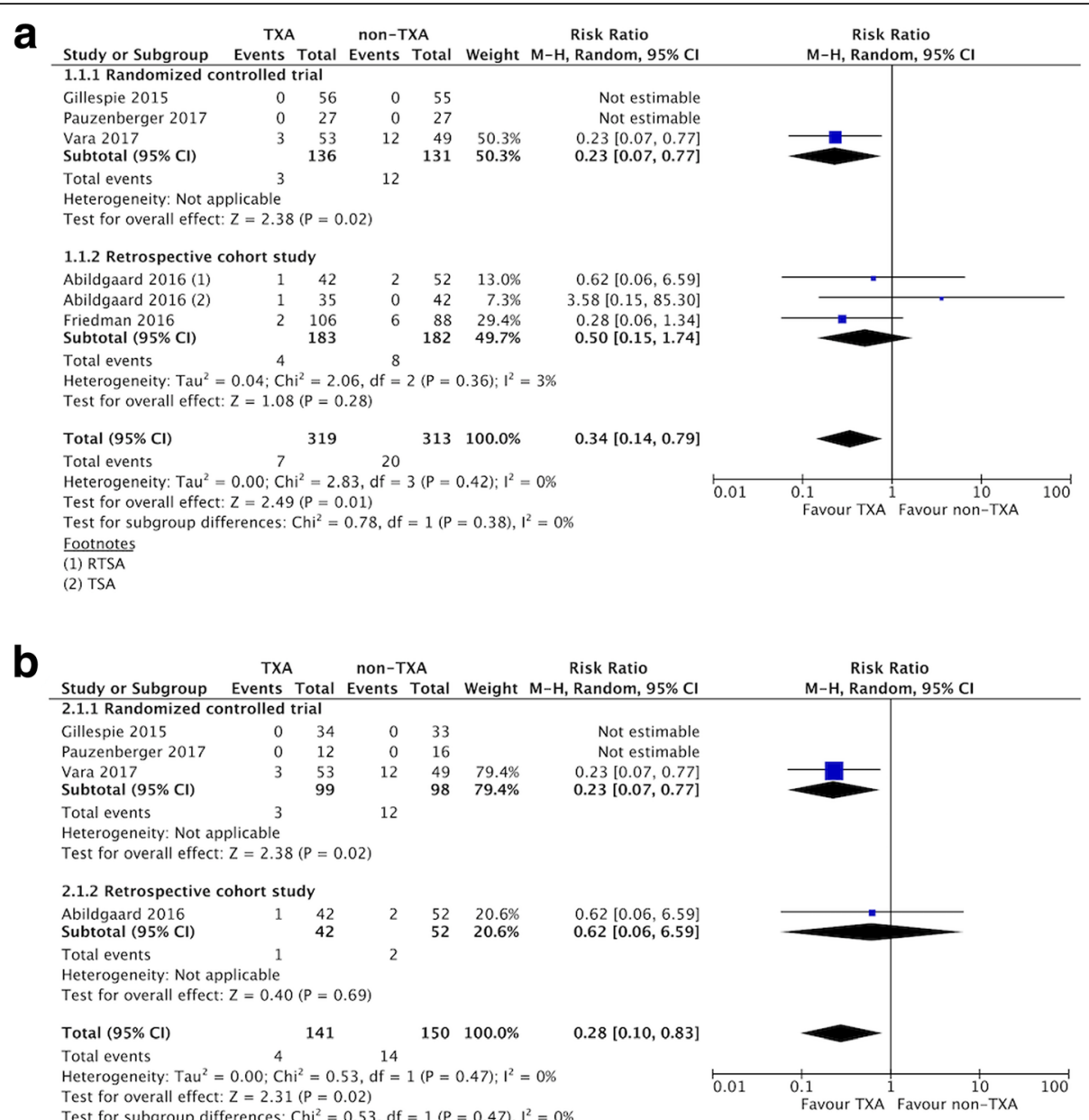

Fig. 3 Forest plot and meta-analysis of the rate of blood transfusion. a All included studies (b) RTSA group

\section{Changes in $\mathbf{H b}$ (within $\mathbf{4 8} \mathrm{h}$ after surgery)}

Five studies reported changes in $\mathrm{Hb}$ within $48 \mathrm{~h}$ after surgery $[19,20,24,33,34]$, with a pooled MD of $-0.64 \mathrm{~g} / \mathrm{dl}$ ( $95 \%$ CI -0.81 to $-0.46 \mathrm{~g} / \mathrm{dl} ; P<0.00001 ; I^{2}=0 \%$; Fig. $5 \mathrm{a}$ ). This indicated that the postoperative decrease in $\mathrm{Hb}$ was $0.64 \mathrm{~g} / \mathrm{dl}$ lower in the TXA group compared to the nonTXA group.

\section{Blood loss via drainage (within $48 \mathrm{~h}$ after surgery)}

Three RCTs [20, 23, 34] and one RCS [24] compared blood loss in drainage in the TXA and the non-TXA groups, which consisted of 160 and 155 patients, respectively. The pooled MD of blood loss via drainage was - $95.41 \mathrm{ml}(95 \%$ CI -139.86 to $-50.96 \mathrm{ml} ; P=0.04 ; I^{2}=65 \%$; Fig. $6 \mathrm{a}$ ), indicating that postoperative blood loss via drainage was $95.41 \mathrm{ml}$ lower in the TXA group within $48 \mathrm{~h}$ after surgery.

\section{Operative time and hospital stay}

Of the included studies, three compared operative time between the two groups [19, 24, 34]. The pooled data showed that there was no significant difference between the two groups (MD - $1.08 \mathrm{~min}, 95 \% \mathrm{CI}$ -4.91 to $2.74 \mathrm{~min} ; P=0.58 ; I^{2}=0 \%$; Fig. 7 ). Two studies compared the hospital stay between the two groups [19, 34], and the pooled data indicated that there was no significant difference regarding hospital stay between the two groups (MD - 0.04 days, 95\% CI -0.45 to 0.37 days; $P=0.84 ; I^{2}=75 \%$; Fig. 8 ).

\section{Overall complications and thromboembolic events}

All six included studies reported data on the proportion of patients who developed complications and thromboembolic events during the study period. There were no significant differences in overall complications or thromboembolic events between the TXA and the non-TXA groups (overall complications: $1 / 343$ vs. $3 / 337$, RR $0.44,95 \%$ CI 0.07 to 2.96; $P=0.95$; $I^{2}=0 \%$; Fig. 9a; thromboembolic events: $0 / 343$ vs. $1 / 337$, RR $0.31,95 \%$ CI 0.01 to $7.40 ; P=0.47$; Fig. $9 \mathrm{~b})$. 


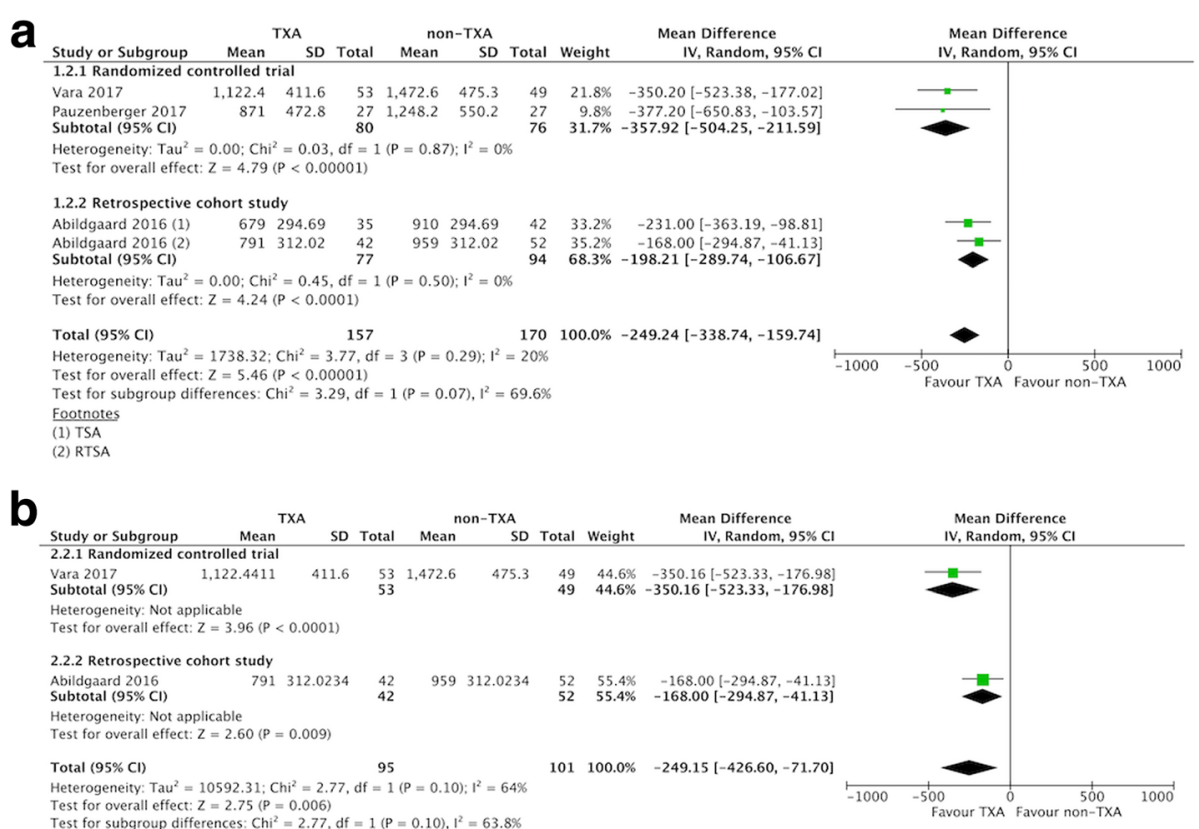

Fig. 4 Forest plot and meta-analysis of estimated total blood loss. a All included studies (b) RTSA group

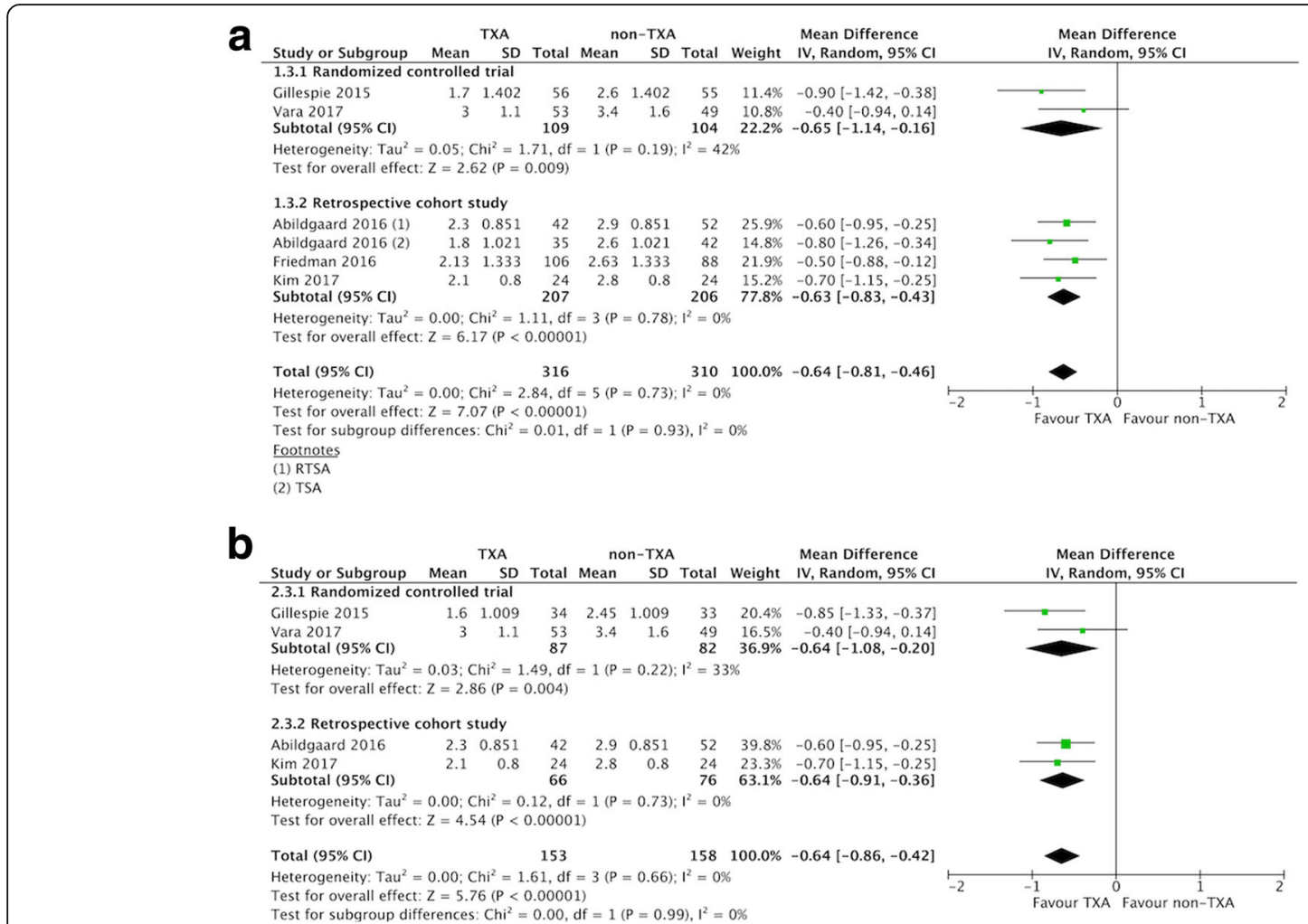

Fig. 5 Forest plot and meta-analysis of Hb change. a All included studies (b) RTSA group (data from Gillespie 2015 were estimated from median and range) 

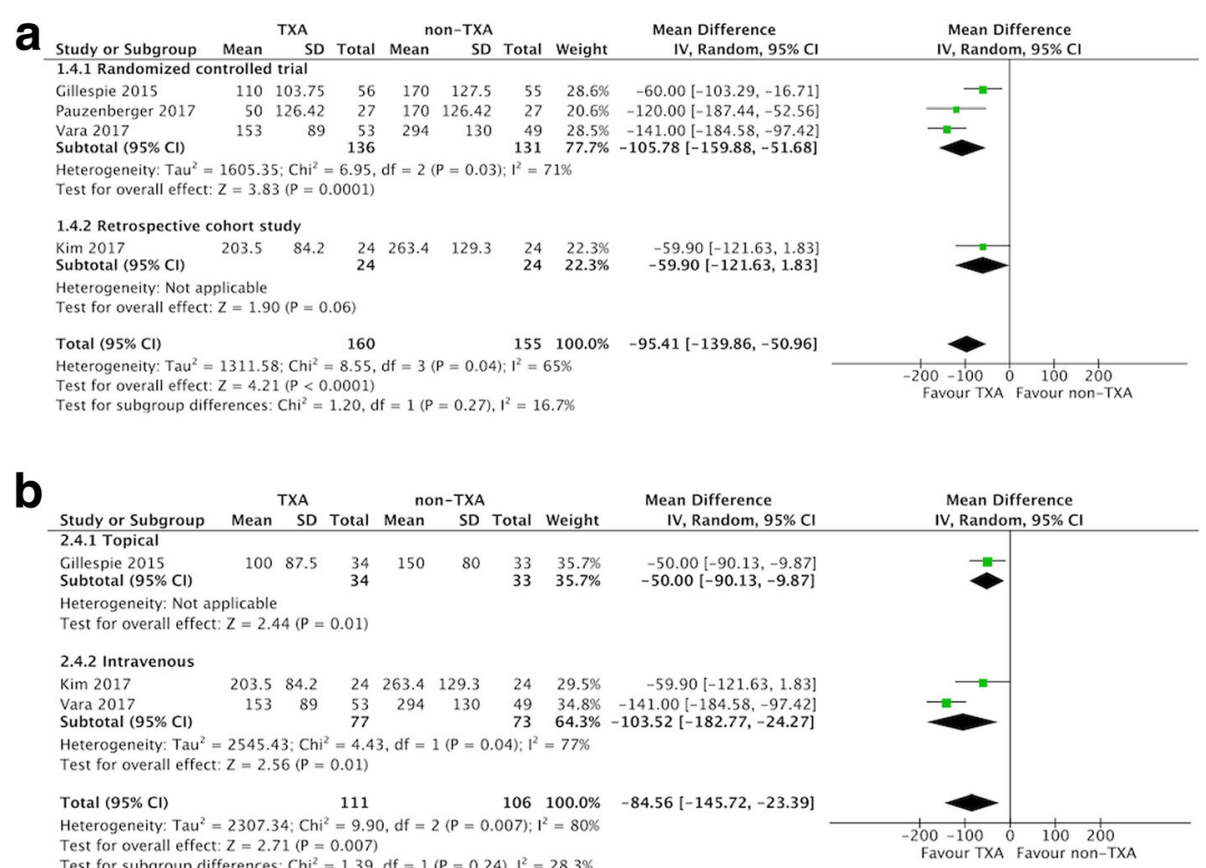

Fig. 6 Forest plot and meta-analysis of blood loss via drainage. a All included studies (b) RTSA group (data from Gillespie 2015 and Friedman 2017 were estimated from median and range)

\section{Subgroup analysis}

Subgroup analysis only including the three RCTs $[20,23,34]$ did not affect the direction of effects of any of the outcomes including allogeneic blood transfusion rate, estimated total blood loss, change in postoperative $\mathrm{Hb}$, and overall complications (Table 3). For data limited to RTSA, the TXA group had a lower allogenic blood transfusion rate, less estimated total blood loss, less change in $\mathrm{Hb}$, and less blood loss via drainage compared with the non-TXA group (Table 3, Fig. 3-6b).

Considering the route of TXA administration, one study examined the topical use of TXA [20], and the other four studies examined the IV administration of TXA $[19,23,24,33,34]$. Regardless of whether topical or IV administration was used, the TXA group had less change in $\mathrm{Hb}$ than the non-TXA group, and there was no difference between the two routes of administration (subgroup difference, $P=0.27$; Table 3 , see Additional file 2: Figure S1). Four studies reported blood loss via drainage [20, 23, 24, 34]. The TXA group had less blood loss compared with the non-TXA group in both topical and IV subgroups (MD $-60.00 \mathrm{ml}, 95 \% \mathrm{CI}-103.29$ to $16.71 \mathrm{ml}, P=0.007$; MD $-110.04 \mathrm{ml}, 95 \% \mathrm{CI}-159.03$ to $61.06 \mathrm{ml}, P<0.0001$, respectively; Table 3, see Additional file 3: Figure S2). Comparing these two subgroups, IV TXA was as effective as topical TXA in reducing blood loss via drainage (subgroup difference, $P=0.13$, Table 3 , see Additional file 3: Figure S2).

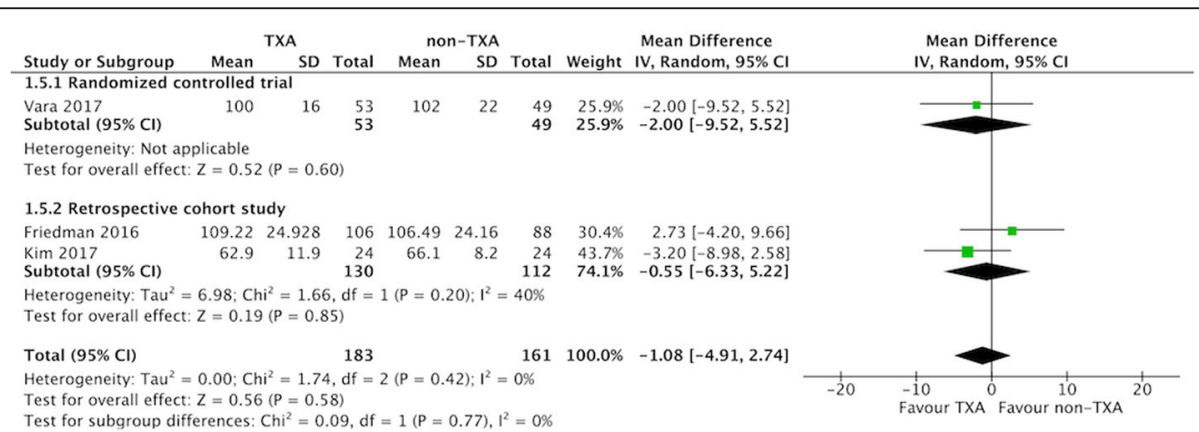

Fig. 7 Forest plot of and meta-analysis of operative time 


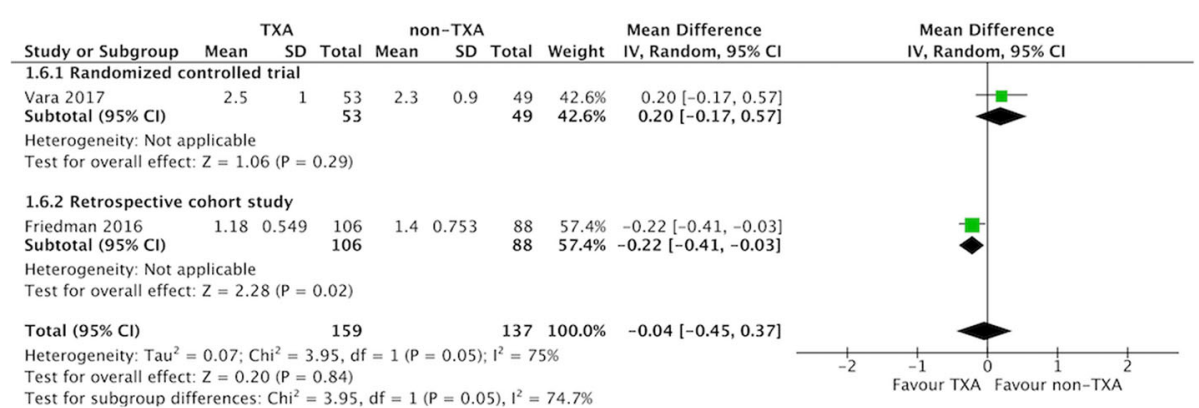

Fig. 8 Forest plot of and meta-analysis of hospital stay

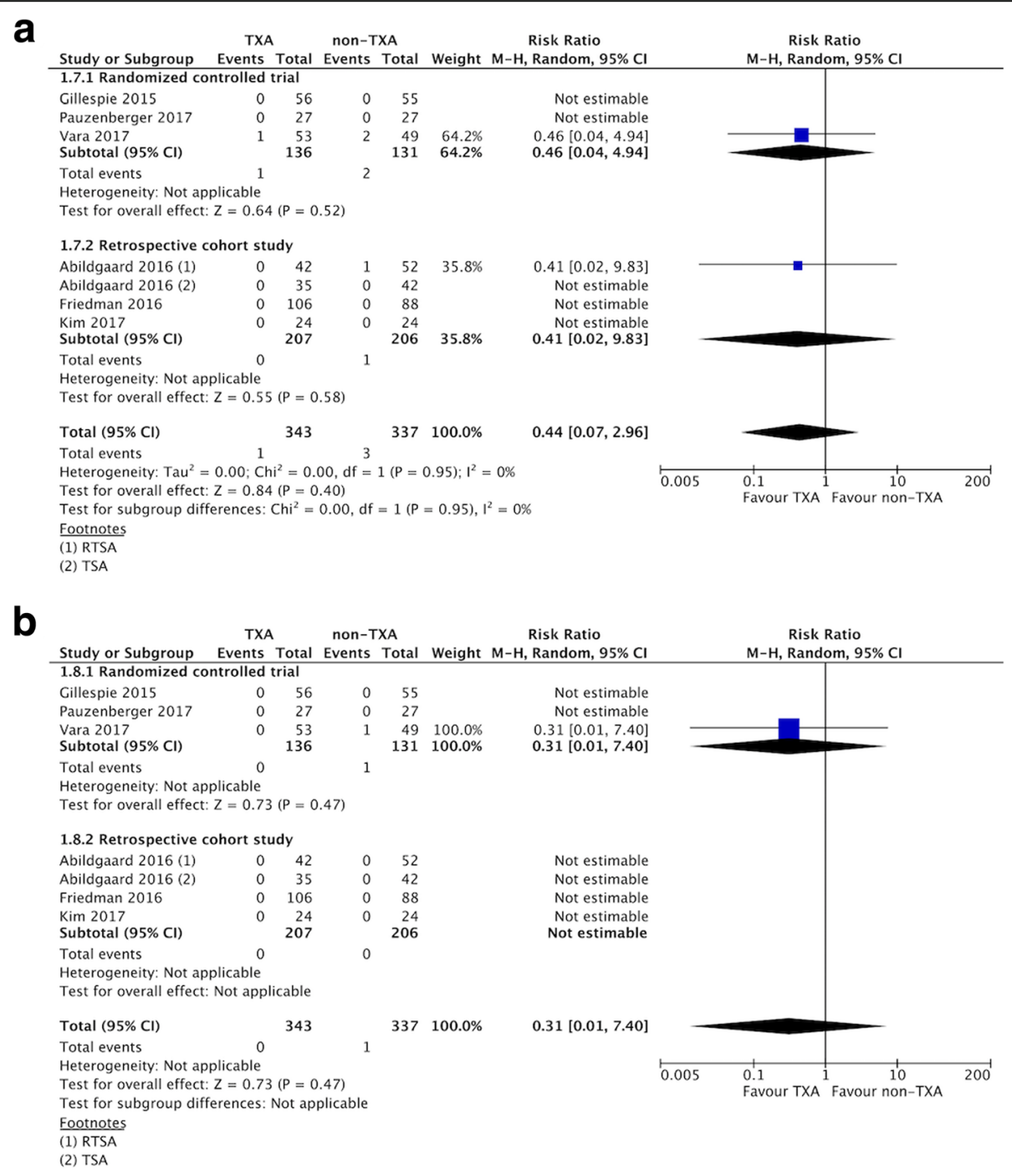

Fig. 9 a Forest plot and meta-analysis of overall complications. b Forest plot and meta-analysis of thromboembolic complications 


\section{Discussion}

The main findings of this study are that the use of TXA in shoulder arthroplasty can reduce blood loss parameters including allogeneic blood transfusion rate, estimated total blood loss, change in $\mathrm{Hb}$ level, and blood loss via drainage without increasing the operative time, hospital stay, or the incidence of perioperative complications.

RTSA has been reported to be an independent predictor of the need for a blood transfusion after shoulder arthroplasty [2], which implied that patients undergoing RTSA bled more than TSA. Both the reverse design of implant geometry and the lack of intact cuff contribute to greater potential dead space in RTSA, resulting in more bleeding [24]. Our study shows that TXA reduces blood loss and the need for blood transfusion, suggesting that it could be applied to patients undergoing RTSA.

TXA has been shown to reverse the effect of plasminogen, thereby reducing blood loss and requirement for an allogeneic blood transfusion [35]. However, the most appropriate route of TXA administration is still under debate. One meta-analysis comparing the effectiveness and safety of IV versus topical administration of TXA in patients undergoing total knee arthroplasty showed that both IV and topical TXA had comparable efficacy in reducing blood loss and blood transfusion rates [36]. Another meta-analysis on total hip and knee arthroplasty also demonstrated similar results [37]. In the present study, both the IV and topical administration of TXA were effective in reducing blood loss and transfusion rates. For patients with a history of pulmonary embolism (PE) or deep vein thrombosis (DVT), the topical administration of TXA may be preferable.

Theoretically, TXA has a potential risk of thrombosis [14]. However, previous studies on total knee or total hip arthroplasty have not found an increased risk of thromboembolic events [16, 36-38]. Our findings suggest that TXA may not increase the risk of venous thromboembolic complications including PE and DVT in shoulder arthroplasty. This may be due to the use of allogeneic blood transfusion protocols with thromboprophylaxis including heparin, aspirin and mechanical prophylaxis in most of the included studies [23, 33, 34]. The low incidence of thromboembolic events may also be due to the routine use of chemical prophylaxis or the careful selection of patients with a higher risk of thromboembolism or the different nature between upper limb and lower limb surgery. In one study investigating the use of TXA in patients undergoing total hip arthroplasty without chemical prophylaxis for DVT, TXA was found to significantly increase the incidence of total DVT compared with the control group [39]. Since we found that both IV TXA and topical TXA were effective in reducing blood loss and transfusion rates, the topical administration of TXA may be preferable for patients with a history of PE or DVT.
To the best of our knowledge, this study is the most up-to-date systematic review and meta-analysis focusing on the use of TXA in shoulder arthroplasty. Compared to the previous systematic review, this study provides additional information about the efficacy of TXA with regards to the different types of shoulder arthroplasty and different routes of administration. This study also provides evidence supporting that TXA is a safe and efficient agent in reducing perioperative blood loss and transfusion rates without increasing complications, and that it can be applied in shoulder arthroplasty, especially for those at risk of requiring a blood transfusion.

This study has several important limitations. First, of the six studies, three were observational, with bias leading to inherent heterogeneity, even with highquality scores. However, the subgroup analysis only including RCTs did not affect the direction of effects of any of the outcomes. In addition, we identified two ongoing trials from trial registries (NCT02569658, NCT01937559), and the findings of the present study may be different after including the results of these two trials. Second, the current study provides information on the route of TXA administration. However, this study can only provide indirect evidence about the comparison between the efficacy of IV TXA and topical TXA. Further trials with direct comparisons between IV TXA and topical TXA are needed to validate this finding. Finally, this study cannot make any conclusions on the optimal dose of TXA. Further head-to-head trials comparing different doses of TXA in shoulder arthroplasty are required to determine the optimal dose. Other limitations included non-standardized doses of TXA, variable postoperative chemoprophylaxis, and heterogeneous transfusion protocols which may have a significant effect on one of the main study endpoints.

\section{Conclusions}

When used in shoulder arthroplasty, TXA is safe and effective in reducing perioperative blood loss and the need for a blood transfusion without increasing complications including thromboembolic events. TXA can be included as part of a comprehensive strategy for shoulder arthroplasty, especially for patients at a high risk of requiring a blood transfusion.

\section{Additional files}

Additional file 1: Appendix 1. Database search strategy. (DOC $211 \mathrm{~kb}$ )

Additional file 2: Figure S1. Forest plot and meta-analysis of $\mathrm{Hb}$ change. The TXA group had a lower change in $\mathrm{Hb}$ than the non-TXA group in both the topical TXA and IV TXA subgroups. There was no significant subgroup difference. (data from Gillespie 2015 and Friedman 2017 were estimated from median and range). (TIFF $1923 \mathrm{~kb}$ ) 
Additional file 3: Figure S2. Forest plot and meta-analysis of blood loss via drainage. The TXA group had less blood loss via drainage than the non-TXA group in both topical TXA and IV TXA subgroups. There was no significant subgroup difference. (data from Gillespie 2015 and Friedman 2017 were estimated from median and range). (TIFF $1562 \mathrm{~kb}$ )

\section{Abbreviations}

Cl: Confidence interval; CTA: Cuff tear arthropathy; DP: Deltopectoral approach; ETBL: Estimated total blood loss; F: Female; Hb: Hemoglobin; Hct: Hematocrit; IV: Intravenous; M: Male; MD: Mean difference; N: Number of studies; N/S: Not shown; NA: Not applicable; NS: Normal saline; OA: Osteoarthritis; ON: Osteonecrosis; RA: Rheumatoid arthritis; RTSA: Reverse total shoulder arthroplasty; TSA: Total shoulder arthroplasty; TXA: Tranexamic acid

\section{Acknowledgements}

We thank Ms. Yu-Shiun Tsai for help in the searching the databases and obtaining the full-text of the articles.

\section{Funding}

No funding was obtained for this study.

\section{Availability of data and materials}

Not applicable

\section{Authors' contributions}

LTK was responsible for the study concept and design and drafting of the manuscript. LTK and WHH were responsible for the trial selection and appraisal of methodological quality. LTK and CCC participated in acquisition, analysis, and interpretation of data. CCC provided consultation for statistics and methodology. CCC and JCY were in charge of the study concept and design, supervised the study and critically revised the manuscript for important intellectual content. All authors read and approved the final manuscript.

\section{Ethics approval and consent to participate}

Not applicable

\section{Consent for publication}

Not applicable

\section{Competing interests}

The authors declare that they have no competing interests.

\section{Publisher's Note}

Springer Nature remains neutral with regard to jurisdictional claims in published maps and institutional affiliations.

\section{Author details}

'Division of Sports Medicine, Department of Orthopedic Surgery, Chang Gung Memorial Hospital, Chiayi, Taiwan. ${ }^{2}$ Centre for Evidence-Based Medicine, Chang Gung Memorial Hospital, Chiayi, Taiwan. ${ }^{3}$ Chang Gung University of Science and Technology, Chiayi, Taiwan. ${ }^{4}$ College of Medicine, Chang Gung University, Taoyuan, Taiwan. ${ }^{5}$ Department of Dermatology, Chang Gung Memorial Hospital, Linkou, 5, Fuxing St, Guishan Dist, Taoyuan 33305, Taiwan. ${ }^{6}$ Department of Orthopedic Surgery, College of Medicine, Samsung Medical Center, Sungkyunkwan University School of Medicine, 81 Irwon-ro, Gangnam-gu, Seoul 135-710, Republic of Korea.

\section{Received: 5 October 2017 Accepted: 8 February 2018}

\section{Published online: 17 February 2018}

\section{References}

1. Ahmadi S, Lawrence TM, Sahota S, Schleck CD, Harmsen WS, Cofield RH, et al. The incidence and risk factors for blood transfusion in revision shoulder arthroplasty: our institution's experience and review of the literature. J Shoulder Elb Surg. 2014;23:43-8.

2. Gruson Kl, Accousti K, Parsons BO, Pillai G, Flatow EL. Transfusion after shoulder arthroplasty: an analysis of rates and risk factors. J Shoulder Elb Surg. 2009;18:225-30.
3. Hardy JC, Hung M, Snow BJ, Martin CL, Tashjian RZ, Burks RT, et al. Blood transfusion associated with shoulder arthroplasty. J Shoulder Elb Surg. 2013; 22:233-9.

4. Millett PJ, Porramatikul M, Chen N, Zurakowski D, Warner JJ. Analysis of transfusion predictors in shoulder arthroplasty. J Bone Joint Surg Am. 2006; 88:1223-30.

5. Ryan DJ, Yoshihara H, Yoneoka D, Zuckerman JD. Blood transfusion in primary total shoulder arthroplasty: incidence, trends, and risk factors in the United States from 2000 to 2009. J Shoulder Elb Surg. 2015;24(5):760.

6. Schumer RA, Chae JS, Markert RJ, Sprott D, Crosby LA. Predicting transfusion in shoulder arthroplasty. J Shoulder Elb Surg. 2010;19:91-6.

7. Sperling JW, Duncan SF, Cofield RH, Schleck CD, Harmsen WS. Incidence and risk factors for blood transfusion in shoulder arthroplasty. J Shoulder Elb Surg. 2005;14:599-601.

8. Kandil A, Griffin JW, Novicoff WM, Brockmeier SF. Blood transfusion after total shoulder arthroplasty: which patients are at high risk? Int I Shoulder Surg. 2016 Apr-Jun;10(2):72-7.

9. Carson JL, Grossman BJ, Kleinman S, Tinmouth AT, Marques MB, Fung MK, et al. Red blood cell transfusion: a clinical practice guideline from the AABB. Ann Intern Med. 2012;157:49-58.

10. National Heart, Lung, and Blood Institute. What are the risks of a blood transfusion? 2012. https://www.nhlbi.nih.gov/health/health-topics/topics/bt/ risks. Accessed 05 May 2017.

11. Grier AJ, Bala A, Penrose CT, Seyler TM, Bolognesi MP, Garrigues GE. Analysis of complication rates following perioperative transfusion in shoulder arthroplasty. J Shoulder Elbow Surg. 2017. pii: S1058-2746(16)30612-7.

12. Kopanidis P, Hardidge A, McNicol L, Tay S, McCall P, Weinberg L. Perioperative blood management programme reduces the use of allogenic blood transfusion in patients undergoing total hip and knee arthroplasty. J Orthop Surg Res. 2016;11:28.

13. Moonen AF, Neal TD, Pilot P. Perioperative blood management in elective orthopaedic surgery. A critical review of the literature. Injury. 2006;37(Suppl 5):S11-6.

14. Mannucci PM. Hemostatic drugs. N Engl J Med. 1998;339:245-53.

15. Alshryda S, Sarda P, Sukeik M, Nargol A, Blenkinsopp J, Mason JM. Tranexamic acid in total knee replacement: a systematic review and metaanalysis. J Bone Joint Surg Br. 2011;93:1577-85.

16. Chen S, Wu K, Kong G, Feng W, Deng Z, Wang H. The efficacy of topical tranexamic acid in total hip arthroplasty: a meta-analysis. BMC Musculoskelet Disord. 2016;17:81. https://doi.org/10.1186/s12891-016-0923-0.

17. Sukeik M, Alshryda S, Haddad FS, Mason JM. Systematic review and metaanalysis of the use of tranexamic acid in total hip replacement. J Bone Joint Surg Br. 2011;93:39-46.

18. Yang ZG, Chen WP, Wu LD. Effectiveness and safety of tranexamic acid in reducing blood loss in total knee arthroplasty: a meta-analysis. J Bone Joint Surg Am. 2012;94:1153-9.

19. Friedman RJ, Gordon E, Butler RB, Mock L, Dumas B. Tranexamic acid decreases blood loss after total shoulder arthroplasty. J Shoulder Elb Surg. 2016:25(4):614-8.

20. Gillespie R, Shishani Y, Joseph S, Streit JJ, Gobezie R. Neer award 2015: a randomized, prospective evaluation on the effectiveness of tranexamic acid in reducing blood loss after total shoulder arthroplasty. J Shoulder Elb Surg. 2015;24(11):1679-84.

21. Sun CX, Zhang L, Mi LD, Du GY, Sun XG, He SW. Efficiency and safety of tranexamic acid in reducing blood loss in total shoulder arthroplasty: a systematic review and meta-analysis. Med (Baltimore). 2017;96(22):e7015. https://doi.org/10.1097/MD.0000000000007015.

22. Kirsch JM, Bedi A, Horner N, Wiater JM, Pauzenberger L, Koueiter DM, et al. Tranexamic acid in shoulder arthroplasty: a systematic review and metaanalysis. JBJS Rev. 2017 Sep;5(9):e3. https://doi.org/10.2106/JBJS.RWW.17.00021.

23. Pauzenberger L, Domej MA, Heuberer PR, Hexel M, Grieb A, Laky B, et al. The effect of intravenous tranexamic acid on blood loss and early postoperative pain in total shoulder arthroplasty. Bone Joint J. 2017 Aug;99-B(8): 1073-9.

24. Kim SH, Jung WI, Kim YJ, Hwang DH, Choi YE. Effect of tranexamic acid on hematologic values and blood loss in reverse Total shoulder arthroplasty. Biomed Res Int. 2017;2017:9590803. https://doi.org/10.1155/2017/9590803.

25. Higgins JP, Altman DG, Gøtzsche PC, Jüni P, Moher D, Oxman AD, Savovic J, Schulz KF, Weeks L, Sterne JA. Cochrane bias methods group. Cochrane Statistical Methods Group The Cochrane Collaboration's tool for assessing risk of bias in randomised trials BMJ. 2011;343:d5928. 
26. Higgins JP, Green S. Cochrane Handbook for Systematic Reviews of Interventions Version 5.1.0. The Cochrane Collaboration. 2011. http://www. cochrane-handbook.org. Accessed 15 Aug 2017.

27. Wells GA, Shea B, O'Connell D, Peterson J, Welch V, Losos M, et al. The Newcastle-Ottawa scale (NOS) for assessing the quality of nonrandomised studies in meta-analyses. Ottawa Hospital Research Institute; 2014. http://www. ohri.ca/programs/clinical_epidemiology/oxford.asp. Accessed 15 Aug 2017.

28. Higgins JP, Thompson SG. Quantifying heterogeneity in a meta-analysis. Stat Med. 2002;21:1539-58.

29. Higgins JP, Thompson SG, Deeks JJ, Altman DG. Measuring inconsistency in meta-analyses. BMJ. 2003;327:557-60

30. DerSimonian R, Laird N. Meta-analysis in clinical trials. Control Clin Trials. 1986;7:177-88

31. Hozo SP, Djulbegovic B, Hozo I. Estimating the mean and variance from the median, range, and the size of a sample. BMC Med Res Methodol. 2005:5:13.

32. Moher D, Liberati A, Tetzlaff J, Altman DG, PRISMA Group. Preferred reporting items for systematic reviews and meta-analyses: the PRISMA statement. PLoS Med. 2009;6(7):e1000097. https://doi.org/10.1371/journal. pmed.1000097.

33. Abildgaard JT, McLemore R, Hattrup SJ. Tranexamic acid decreases blood loss in total shoulder arthroplasty and reverse total shoulder arthroplasty. J Shoulder Elb Surg. 2016 Oct;25(10):1643-8.

34. Vara AD, Koueiter DM, Pinkas DE, Gowda A, Wiater BP, Wiater JM. Intravenous tranexamic acid reduces total blood loss in reverse total shoulder arthroplasty: a prospective, double-blinded, randomized, controlled trial. J Shoulder Elb Surg. 2017:26:1383-9.

35. Nuttall GA, Brost BC, Connis RT, Gessner JS, Harrison CR, Miller RD, et al. Practice guidelines for perioperative blood transfusion and adjuvant therapies: an updated report by the American Society of Anesthesiologists Task Force on perioperative blood transfusion and adjuvant therapies. Anesthesiology. 2006 Jul;105(1):198-208.

36. Shin YS, Yoon JR, Lee HN, Park SH, Lee DH. Intravenous versus topical tranexamic acid administration in primary total knee arthroplasty: a metaanalysis. Knee Surg Sports Traumatol Arthrosc. 2016; https://doi.org/10.1007/ s00167-016-4235-6.

37. Chen Y, Chen Z, Cui S, Li Z, Yuan Z. Topical versus systemic tranexamic acid after total knee and hip arthroplasty: a meta-analysis of randomized controlled trials. Med (Baltimore). 2016 Oct;95(41):e4656. https://doi.org/10.1097/MD. 0000000000004656.

38. Kim TK, Chang CB, Koh IJ. Practical issues for the use of tranexamic acid in total knee arthroplasty: a systematic review. Knee Surg Sports Traumatol Arthrosc. 2014 Aug;22(8):1849-58

39. Nishihara S, Hamada M. Does tranexamic acid alter the risk of thromboembolism after total hip arthroplasty in the absence of routine chemical thromboprophylaxis? Bone Joint J. 2015 Apr;97-B(4):458-62.

\section{Submit your next manuscript to BioMed Central and we will help you at every step:}

- We accept pre-submission inquiries

- Our selector tool helps you to find the most relevant journal

- We provide round the clock customer support

- Convenient online submission

- Thorough peer review

- Inclusion in PubMed and all major indexing services

- Maximum visibility for your research

Submit your manuscript at www.biomedcentral.com/submit

) Biomed Central 